\title{
Susceptibility to amphotericin B of Candida spp. strains isolated in Ceará, Northeastern Brazil
}

\author{
Cecília Rocha da Silva ${ }^{[1]}$, Hemerson lury Ferreira Magalhães ${ }^{[1],[2],}$ \\ Manoel Odorico de Moraes ${ }^{[2]}$ and Hélio Vitoriano Nobre Júnior ${ }^{[1],[2]}$
}

[1]. Laboratório de Bioprospecção e Experimentação em Leveduras, Departamento de Análises Clinicas e Toxicológicas, Faculdade de Farmácia, Universidade Federal de Ceará, Fortaleza, CE. [2]. Departamento de Fisiologia e Farmacologia, Universidade Federal do Ceará, Fortaleza, CE.

\begin{abstract}
Introduction: Amphotericin B (AMB) is an antifungal agent used extensively in clinical medicine, yet resistance remains low. This study aims to evaluate the susceptibility of Candida spp. against AMB. Methods: For broth microdilution susceptibility testing, 77 strains of Candida spp. were selected (32 C. albicans, 33 C. tropicalis, and 12 C. parapsilosis). The strains were considered susceptible when they exhibited MIC $\leq 1.0 \mu \mathrm{g} / \mathrm{ml}$. Results: None of the strains showed an MIC greater than $0.25 \mu \mathrm{g} / \mathrm{ml}$. Conclusions: Further works are necessary, with a higher number of strains, to assess the validity of the results used in this study.
\end{abstract}

Keywords: Amphotericin B. Candida spp. Protocol M27-A3.

Amphotericin B (AMB) is a polyene macrolide antifungal agent, isolated from Streptomyces nodosus, collected in 1955 from the Orinoco river delta in Venezuela. AMB was quickly introduced in clinical medicine, receiving approval from the Food and Drug Administration (FDA) in 1958, even without the elucidation of its chemical structure. AMB has been and still remains the gold standard for the treatment of IFIs. It presents a broad spectrum of action and low incidence of fungal resistance after a half century of clinical use. Its primary drawback is nephrotoxicity ${ }^{1,2}$.

Clinical and Laboratory Standards Institute (CLSI) developed a document in 2006, classified as M27-A2, which describes the ranges and breakpoints of the antifungal agents used to treat invasive fungal infections (IFIs) caused by Candida spp. and Cryptococcus spp.; there is nothing for the other fungal species. For AMB, the document defined a range from 0.03 to $16 \mu \mathrm{g} / \mathrm{mL}$; breakpoints were not defined. In 2008, a new document was published, M27-A3, which did not contain the breakpoints for AMB. The supplement to that document, M27-S3, also includes nothing on the breakpoints, which makes it difficult to assess AMBresistant strains ${ }^{3,4}$. This study aims to assess the susceptibility to AMB of Candida spp. strains isolated in State of Ceará.

A total of 77 strains of Candida spp. were selected (32 C. albicans, 33 C. tropicalis, and 12 C. parapsilosis); these are the strains most commonly isolated from fungal infections in State of Ceará. The strains were isolated from blood, urine, respiratory tract, and catheter tip between 2009 and 2010

Address to: Dr. Hélio Vitoriano Nobre Júnior. Rua Capitão Francisco Pedro 1210, Rodolfo Teófilo, 060420-970 Fortaleza, CE, Brasil.

Phone: 5585 3366-8266; Fax: 5585 3366-8292

e-mail: helioufc@yahoo.com.br

Received 06 April 2011

Accepted 17 May 2011 and are part of the collection of yeasts of the Laboratory of Bioprospecting of Megamicrodiversity of Ceará, College of Pharmacy, Federal University of Ceará (LABMIC/FF/UFC). The strains were inoculated on potato agar (Himedia Mumbai, India) and incubated at $37^{\circ} \mathrm{C} / 24 \mathrm{~h}$. They were then plated on CHROMagar Candida (Himedia Mumbai, India) to assess purity. Identification was done by micromorphology on rice agar Tween 80 , germ tube production, fermentation, and assimilation of carbohydrates, as well as molecular tests ${ }^{5,6}$.

The broth microdilution (BMD) susceptibility testing was performed according to document M27-A3 using the RPMI broth (Cultilab São Paulo, Brazil) (pH 7.0) buffered with 0.165 M morpholinepropanesulfonic acid (MOPS) (Sigma, USA) to assess susceptibility to amphotericin B. The AMB (Inlab, São Paulo) was dissolved in DMSO and diluted in RPMI, and the range tested was $0.03-16 \mu \mathrm{g} / \mathrm{ml}$. The plates were incubated for $24 \mathrm{~h}$ and $48 \mathrm{~h}$, and the results were read visually as recommended by the CLSI. For AMB, the minimum inhibitory concentration (MIC) was considered as the concentration that inhibits $100 \%$ of fungal growth. The CLSI has not determined breakpoints for AMB; the strains were considered susceptible when they had MIC $\leq 1.0 \mu \mathrm{g} / \mathrm{ml}$. The strains C. parapsilosis ATCC 22019 and C. krusei ATCC 6258 were used as controls ${ }^{4,7-9}$.

Table 1 shows the distribution of Candida spp. strains according to the MICs for the periods tested. None of the strains showed MIC greater than $0.25 \mu \mathrm{g} / \mathrm{ml}$ in any of the times tested. The numbers in bold type describe the total number of strains with the same MIC. As can be seen, all strains were susceptible to $\mathrm{AMB}$, and no resistance was detected. The table allows for the proposal of new ranges to be tested for AMB. As no strains with $\mathrm{MIC} \geq 1$ were detected, we propose that the new range for AMB vary from 0.03 to $2 \mu \mathrm{g} / \mathrm{ml}$. The breakpoint adopted in our study has been described by other authors who consider all strains with $\mathrm{MICs} \leq 1.0$ to be susceptible strains. 
TABLE 1 - Correlation of 24-h and 48-h amphotericin MICs with 77 Candida spp

\begin{tabular}{|c|c|c|c|c|c|c|c|c|c|}
\hline \multirow{2}{*}{$\begin{array}{l}\text { 24h MIC } \\
(\mu \mathrm{g} 8 \mathrm{~mL})\end{array}$} & \multicolumn{9}{|c|}{ Number of isolates with 48 -h MIC $(\mu \mathrm{g} 8 \mathrm{~mL})$} \\
\hline & $<0.03$ & 0.06 & 0.12 & 0.25 & 0.5 & 1 & 2 & Total & $\%$ \\
\hline$<0.03$ & 4 & 14 & 22 & 12 & - & - & - & 52 & 67.5 \\
\hline 0.06 & - & 1 & 8 & 8 & - & - & - & 17 & 89.6 \\
\hline 0.12 & - & - & 5 & 3 & - & - & - & 8 & 100.0 \\
\hline 0.25 & - & - & - & - & - & - & - & - & - \\
\hline 0.5 & - & - & - & - & - & - & - & - & - \\
\hline 1 & - & - & - & - & - & - & - & - & - \\
\hline 2 & - & - & - & - & - & - & - & - & - \\
\hline Total & 4 & 15 & 35 & 23 & - & - & - & 77 & - \\
\hline$\%$ & 5.2 & 24.7 & 70.2 & 100.0 & - & - & - & - & - \\
\hline
\end{tabular}

MIC: Minimum inhibitory concentration.

Antifungal susceptibility testing has been a notable advance in the treatment of fungal infections and is the primary tool in the application of appropriate antifungal therapy. Treatment of IFIs requires knowledge of the epidemiology of the fungal species involved and should be done in accordance with the identification of species associated with the result of the antifungal susceptibility testing. This testing is laborious, requiring trained personnel, and is only available for a few fungi ${ }^{10-12}$.

The standardization of susceptibility testing for fungi is still a hotly debated topic. In the past decade, several consensuses have been obtained. However, the ranges of the drugs and the breakpoints are still under discussion ${ }^{4,13}$.

In a study of 5,821 strains of Candida spp., the range tested was from 0.06 to $8 \mu \mathrm{g} / \mathrm{mL}$, and the results were read after $24 \mathrm{~h}$. No breakpoints were determined, and no resistance to AMB was detected; none of the strains exhibited $\mathrm{MIC} \geq 2 \mu \mathrm{g} / \mathrm{ml}^{14}$. In another study of 1,000 strains of Candida spp. isolated in Brazil - in which arbitrary breakpoint values were adopted - no strains showed $\mathrm{MIC} \geq 2 \mu \mathrm{g} / \mathrm{ml}$ for $\mathrm{AMB}^{15}$. In our study, all strains exhibited 24-h MIC of no more than $0.12 \mu \mathrm{g} / \mathrm{ml}$ (Table 1). Our results agree with those found for a higher number of strains.

For AMB, the breakpoint has not been defined, and the test range recommended by the CLSI is 0.03 to $16 \mu \mathrm{g} / \mathrm{ml}$. Studies show that the MICs of susceptible strains are no more than $1 \mu \mathrm{g} / \mathrm{ml}$, and it is unnecessary to use such a broad test range ${ }^{7-9}$. In conclusion, our study has provided additional information on an extremely relevant topic. Further work is necessary, with a higher number of strains, to assess the validity of the ranges and breakpoints used in this study.

\section{CONFLICT OF INTEREST}

The authors declare that there is no conflict of interest.

\section{FINANCIAL SUPPORT}

This study was supported by CNPq, CAPES, and FUNCAP.

\section{REFERENCES}

1. Nicolaou KC, Chen JS, Dalby SM. From nature to the laboratory and into the clinic. Bioorg Med Chem 2009; 17:2290-2303.
2. Volmer AA, Szpilman AM, Carreira EM. Synthesis and biological evaluation of amphotericin B derivatives. Nat Prod Rep 2010; 27:1329-1349.

3. Clinical and Laboratory Standards Institute. Reference method for broth dilution antifungal susceptibility testing of yeasts: approved standard. M27-A2. $2^{\text {nd }}$ ed. Wayne, PA: Clinical and Laboratory Standards Institute; 2006.

4. Clinical and Laboratory Standards Institute. Reference method for broth dilution antifungal susceptibility testing of yeasts: approved standard. M27-A3. $3^{\text {rd }}$ ed. Wayne, PA: Clinical and Laboratory Standards Institute; 2008.

5. Medrano DJA, Brilhante RSN, Cordeiro RA, Rocha MFG, Rabenhorst SHB, Sidrim JJC. Candidemia in a Brazilian hospital: the importance of Candida parapsilosis. Rev Inst Med Trop S Paulo 2006; 48:17-20.

6. Menezes EA, Mendes LG, Cunha FA. Resistência a antifúngicos de Candida tropicalis isoladas no Estado do Ceará. Rev Soc Bras Med Trop 2009; 2:354-355.

7. Yang YL, Wang AH, Wang CH, Cheng WT, Li SY, Lob HJ. Susceptibilities to amphotericin B and fluconazole of Candida species in Taiwan Surveillance of Antimicrobial Resistance of Yeasts 2006. Diagn Microbiol Infect Dis 2008; 61:175-180.

8. Franco MED, Reviákina V, Panizo MM, Macero C, Moreno X, Calvo A, et al. Distribución y sensibilidad a los antifúngicos de aislamientos clínicos de Candida en seis centros de salud del área metropolitana de Caracas, Venezuela (años 2003-2005). Rev Iberoam Micol 2008; 25:17-21.

9. Kiraz N, Dag I, Oz Y, Yamac M, Kiremitci A, Kasifoglu N. Correlation between broth microdilution and disk diffusion methods for antifungal susceptibility testing of caspofungin, voriconazole, amphotericin $\mathrm{B}$, itraconazole and ûuconazole against Candida glabrata. J Microbiol Meth 2010; 82:136-140.

10. Khot PD, Suci PA, Tyler BJ. Candida albicans viability after exposure to amphotericin B: Assessment using metabolic assays and colony forming units. J Microbiol Meth 2008; 72:268-274.

11. Chen SCA, Playford G, Sorrell TC. Antifungal therapy in invasive fungal infections. Curr Opin Pharm 2010; 10:522-530.

12. Laniado-Laborín R, Cabrales-Vargas MN. Amphotericin B: side effects and toxicity. Rev Iberoam Micol 2009; 26:223-227.

13. Pfaller MA, Castanheira M, Messer S, Moet GJ, Jones RN. Echinocandin and triazole antifungal susceptibility profiles for Candida spp., Cryptococcus neoformans, and Aspergillus fumigatus: application of new CLSI clinical breakpoints and epidemiologic cutoff values to characterize resistance in the SENTRY Antimicrobial Surveillance Program (2009). Diagn Microbiol Infect Dis 2011; 69:45-50.

14. Lyon GM, Karatela S, Sunay S, Adiri Y. Antifungal Susceptibility Testing of Candida Isolates from the Candida Surveillance Study. J Clin Microb 2010; 48:1270-1275.

15. Matta DA, Almeida LP, Machado AM, Azevedo AC, Kusano EJ, Travassos NF, et al. Antifungal susceptibility of 1000 Candida bloodstream isolates to 5 antifungal drugs: results of a multicenter study conducted in São Paulo, Brazil, 1995-2003. Diagn Microbiol Infect Dis 2007; 57:399-404. 